\title{
ChemComm
}

\section{Protein $\beta$-interfaces as a generic source of native peptide tectons $\dagger$}

Cite this: Chem. Commun., 2013

Received 18th December 2012,

Accepted 18th February 2013

\author{
Céline Valéry, $^{* a}$ Rishi Pandey ${ }^{a}$ and Juliet A. Gerrard*abcd
}

DOI: $10.1039 / \mathrm{c3cc39052g}$

www.rsc.org/chemcomm

Motifs of 7-8 amino acids were designed from the $\beta$-continuous interfaces of non-related homo-oligomeric proteins. These peptides intrinsically self-assembled into nanoarchitectures in water, while retaining some properties of their parent interfaces, especially reversibility of assembly. These results reveal a novel source of native peptide tectons.

Proteins commonly function as homo-oligomers, with many of these complexes able to dissociate and associate readily in response to changing biological conditions. ${ }^{1}$ Such subtle equilibria rely on finely tuned protein-protein interfaces, which provide the necessary structural versatility through sets of complementary non-covalent interactions. ${ }^{2}$ These protein subunits appear to be optimised by evolution to drive protein self-assembly in a reversible and controlled manner. ${ }^{1,3}$ We hypothesised that the corresponding isolated interface sequences could serve as a source of native self-assembling motifs, or tectons, while retaining some of the parent interface properties as they self-assemble.

Peptide tectons are defined as simple or minimal sequences able to spontaneously self-associate into well-defined nanoscale assemblies. ${ }^{4}$ For the past two decades, peptide chemistry has focused on exploring design principles and sources of such motifs, towards downstream applications in bionanotechnology. ${ }^{5}$ In the specific case of $\beta$-sheet-based motifs, tectons still remain difficult to design outside a few discrete families of bioinspired sequences, such as the cyclic D,L-peptides designed from the pore-forming gramicidin, ${ }^{6}$ the diphenylalanine motif inspired

\footnotetext{
${ }^{a}$ Biomolecular Interaction Centre, University of Canterbury, Private Bag 4800, Christchurch 8140, New Zealand. E-mail: celine.valery@canterbury.ac.nz, juliet.gerrard@canterbury.ac.nz; Tel: +64 33642987

${ }^{b}$ Riddet Institute, Massey University, Palmerston North, New Zealand

${ }^{c}$ MacDiarmid Institute, University of Canterbury, New Zealand

${ }^{d}$ Callaghan Innovation Research Limited, P.O. Box 31310, Lower Hutt 5040, New Zealand

† Electronic supplementary information (ESI) available: Acknowledgements, full experimental details, PDB survey details, birefringence of peptide 3 samples, pH influence on peptide assemblies, TEM analysis of nanostructure reversibility. See DOI: $10.1039 / \mathrm{c} 3 \mathrm{cc} 39052 \mathrm{~g}$
}

from the high aromatic content in amyloid sequences, ${ }^{7}$ the fragments $16-22$ from the $A \beta$ amyloid peptide, ${ }^{8,9}$ the lanreotide peptide family designed as analogues of the self-assembling peptide hormone somatostatin-14, ${ }^{10,11}$ or the surfactant peptides inspired from lipid structures. ${ }^{12}$ Novel generic sources of tectons will therefore widen the current set of available sequences with which to explore specific applications. To design the peptides, we focused on one of the simplest interface motifs, the $\beta$-continuous interface, previously estimated to represent about $15 \%$ of the reported protein oligomeric interfaces. ${ }^{1} \beta$-Continuous interfaces consist of antiparallel non-covalent close contacts of two identical $\beta$-strands from the two interacting protein units (Fig. 1).

From a survey of the entire protein data bank for the key word 'homodimer' that resulted in >800 entries, we downsized the set of proteins to about 20 structures using the following unbiased criteria: (i) selecting native homo-oligomers with $\beta$-continuous interfaces, while excluding structures with ligands, to limit the complexity of the sets of interactions involved; (ii) excluding fragmented and complex interfaces, the latter being defined as involving multiple different
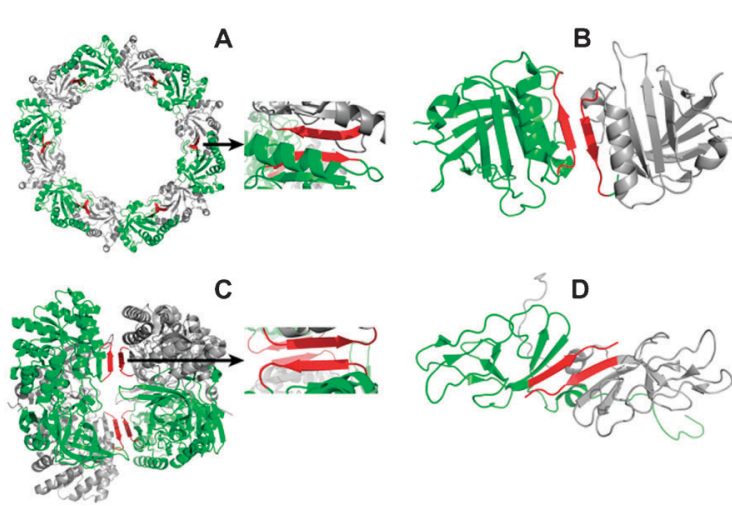

Fig. 1 Protein homo-oligomers (pdb crystal structures for $A-C$, pdb solution structure for D, red: interface contacts according to the software PISA). (A) Peroxiredoxin III homo-dodecamer (1ZYE) (with zoom into the homodimer interface); (B) $\beta$-lactoglobulin homodimer (2Q39); (C) diaminopimelate decarboxylase homo-tetramer (2O0T) (with zoom into the tetramer interface); (D) umud' homodimer (114V). 


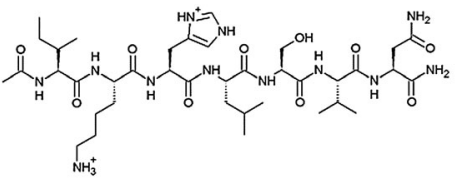

(1)

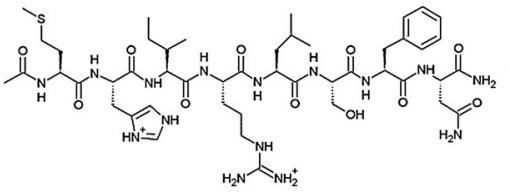
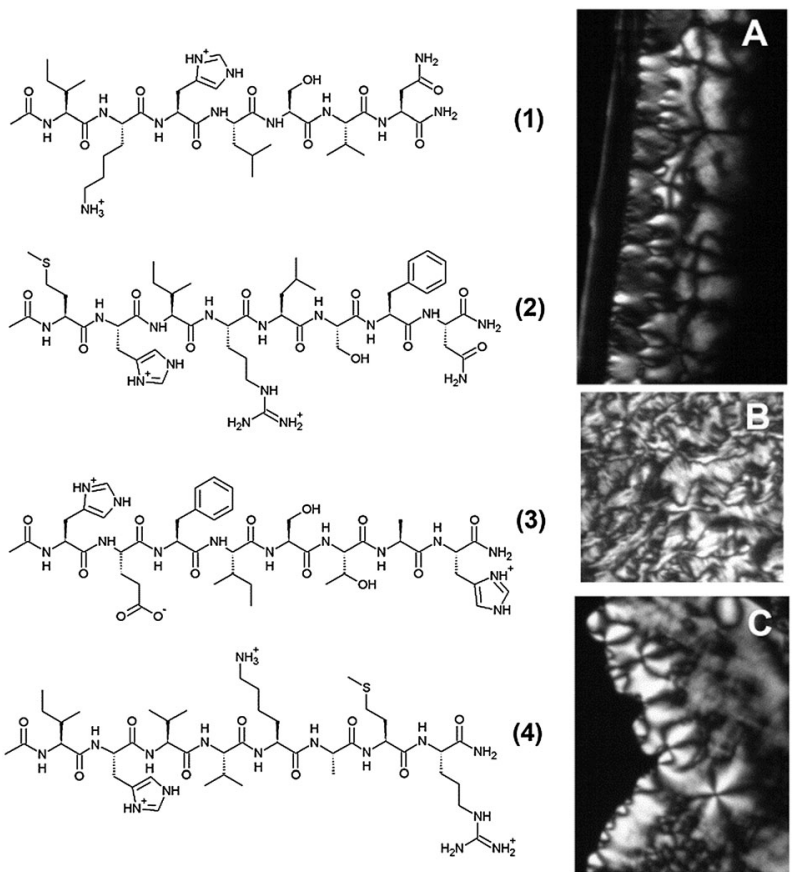

Fig. 2 Left panel: capped peptides designed from the $\beta$-interfaces of bovine peroxiredoxin III (peptide 1), $\beta$-lactoglobulin (peptide 2), TB diaminopimelate decarboxylase (peptide 3 ), and umud' protein (peptide 4). Right panel: liquid crystalline optical textures for (A) peptide 1 at $20 \mathrm{mg} \mathrm{mL}^{-1}$ in water, (B) peptide 2 at $40 \mathrm{mg} \mathrm{mL}^{-1}$, and (C) peptide 4 at $150 \mathrm{mg} \mathrm{mL}^{-1}$. Magnification $\times 100$.

secondary structure motifs; (iii) selecting only one representative interface from families of proteins with high sequence homology, to ensure sequence variety and a valid test of the hypothesis among different protein families. A statistical analysis performed on the interface sequences given by the PISA software for the final set of structures revealed that $90 \%$ contained 11 or fewer residues, $80 \%$ included at least one aromatic residue, all of the sequences contained at least $30 \%$ of hydrophobic residues, and $15 \%$ of charged residues (ESI + ). The finally selected capped sequences (both $\mathrm{N}$-acetylated and $\mathrm{C}$-amidated to conserve the net charge of the corresponding interfaces) were chosen as representative of the entire set of homodimers examined.

The selected peptides of 7-8 residues, respectively, correspond to the $\beta$-continuous interfaces of (i) the bovine peroxiredoxin III homodimer within the dodecameric ring, ${ }^{13}$ (ii) the bovine $\beta$-lactoglobulin homodimer, ${ }^{14,15}$ (iii) the Mycobacterium tuberculosis diaminopimelate decarboxylase homotetramer, ${ }^{16}$ and (iv) the $E$. coli umud' protein homodimer ${ }^{17}$ (Fig. 1 and 2, Table 1).

All the corresponding oligomers exist in solution. ${ }^{16,18-20}$ To our knowledge, none of these peptides or similar sequences have been previously probed for assembly under any condition,
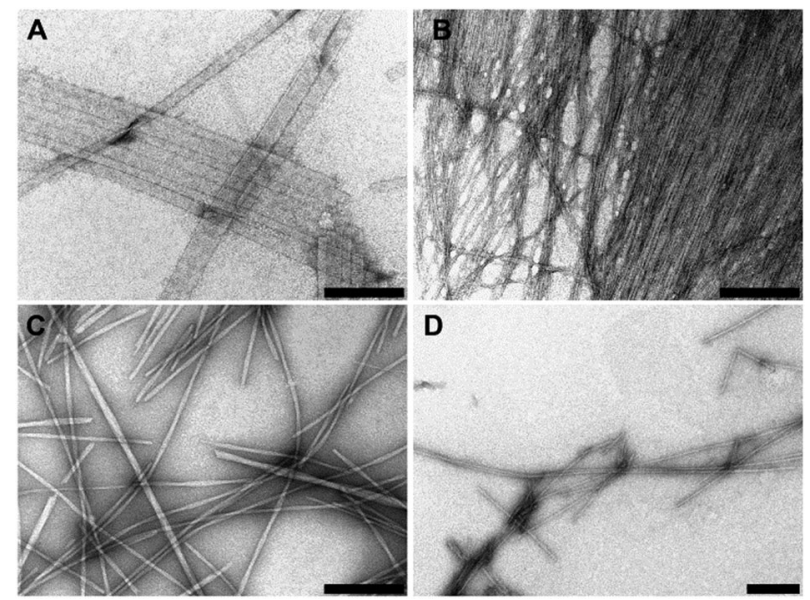

Fig. 3 Transmission electron micrographs of negatively stained (A) peptide 1 at $40 \mathrm{mg} \mathrm{mL}^{-1}$ in water, (B) peptide 2 at $30 \mathrm{mg} \mathrm{mL}^{-1}$ in water, (C) peptide 3 at 200 $\mathrm{mg} \mathrm{mL}^{-1}$ in water, (D) peptide 4 at $100 \mathrm{mg} \mathrm{mL}^{-1}$ in water. Scale bars correspond to $200 \mathrm{~nm}$.

except for a $\beta$-lactoglobulin motif similar to peptide 2 , reported to assemble under denaturing conditions involving urea. ${ }^{21}$

All four peptides formed birefringent hydrogels within the concentration range of $20-200 \mathrm{mg} \mathrm{mL}^{-1}$ in pure water, with liquid crystalline properties observed for at least three of them (Fig. 2A-C, ESI $\dagger$ for peptide 3). Electron microscopy revealed that all four peptides spontaneously self-assemble in pure water into nanostructures with elongated morphologies (Fig. 3): nanoribbons for peptide $\mathbf{1}$, bundles of nanofibrils for peptide 2 , and single nanofibrils for peptides 3 and $\mathbf{4}$. Similar morphologies were obtained in high $\mathrm{pH}$ buffer (ESI $\dagger$ ). These elongated nanostructures fall within the spectrum of morphologies previously reported for $\beta$-sheet self-assembling peptides. $^{22}$

The four peptides exhibited an expected propensity for $\beta$-sheet secondary structures at low concentrations in pure water $\left(0.008 \mathrm{mg} \mathrm{mL}^{-1}\right)$, as shown by the far-UV circular dichroism spectra with negative minima around 215-220 nm (Fig. 4A and B). For the peptide hydrogels, FT-Raman spectra showed sharp amide I vibrations centered at $1660-1670 \mathrm{~cm}^{-1}$, which correspond to extended $\beta$-sheet networks ${ }^{23}$ (Fig. 4C).

In all four cases, the $\beta$-sheet networks were found to dissociate upon dilution, as shown by the ThT binding assays performed by dilution from an initial concentrated sample (1 day old) (Fig. 5). TEM analysis confirmed nanostructure reversibility (ESI $\dagger$ ). Reversibility has been previously reported for a few peptide nanostructures. ${ }^{5,11,24}$ The ThT curves further suggest a higher critical concentration of assembly for peptide 3 than for the other peptides. Interestingly, this result correlates with the type of interface from which the peptides were

Table 1 Proteins and corresponding $\beta$-interfaces chosen as models

\begin{tabular}{|c|c|c|c|}
\hline Proteins and species & PDB code & PDB oligomer & Interface motif (PISA) \\
\hline Peroxiredoxin III (bovine) & 1zye & Dodecamer & IKHLSVN (1) \\
\hline$\beta$-Lactoglobulin (bovine) & $2 \mathrm{q} 39,2 \mathrm{akq}$ & Dimer & MHIRLSFN (2) \\
\hline Diaminopimelate decarboxylase (M. tuberculosis) & $200 t$ & Tetramer & HEFISTAH (3) \\
\hline Umud' (E. coli) & $1 \mathrm{i} 4 \mathrm{v}$ & Dimer & IHVVKAMR (4) \\
\hline
\end{tabular}




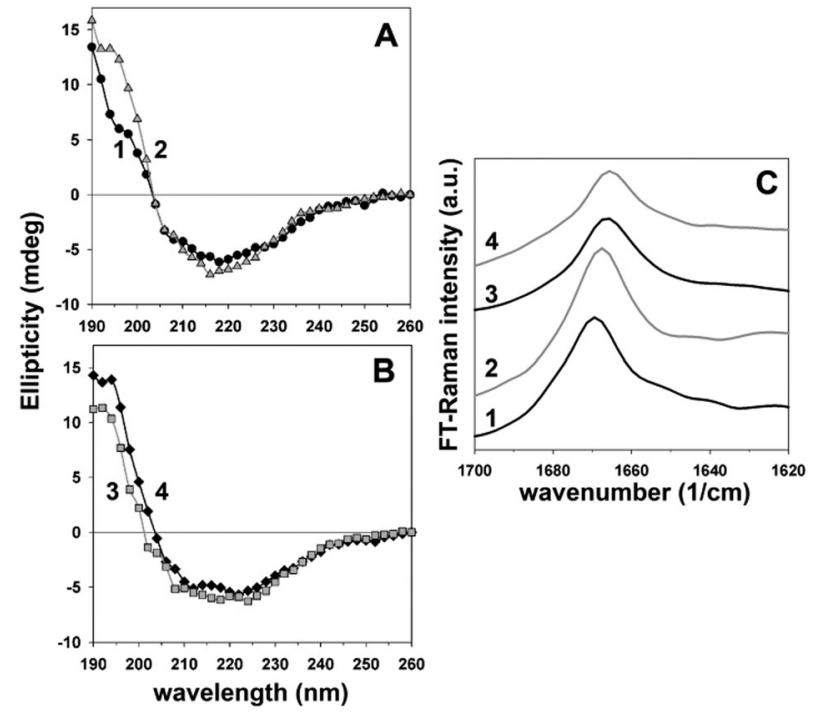

Fig. 4 Peptide conformation. CD spectra at $0.008 \mathrm{mg} \mathrm{mL}^{-1}$ in water of peptides 1 and 2 (A), and peptides 3 and 4 (B). Panel C: FT-Raman amide I vibrations of peptides 1 and 2 at $100 \mathrm{mg} \mathrm{mL}^{-1}$ in water, peptides 3 and 4 at $200 \mathrm{mg} \mathrm{mL}^{-1}$.

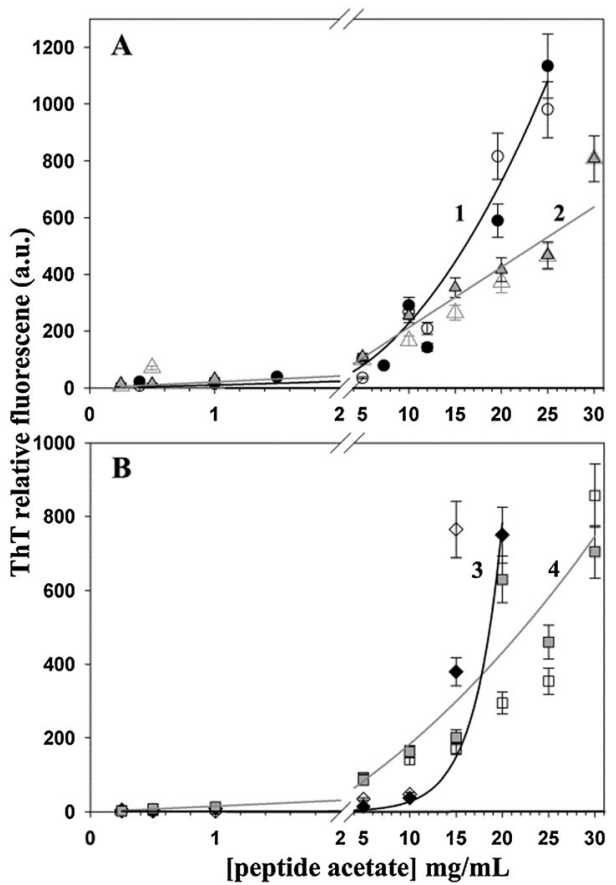

Fig. 5 ThT binding assays upon dilution, for peptides $\mathbf{1}$ and $\mathbf{2}$ (A), and peptides 3 and 4 (B). Fluorescence intensity values just after dilution (white scatters), and $24 \mathrm{~h}$ after dilution (black scatters) of an initial sample equilibrated for $24 \mathrm{~h}$ (highest concentration).

designed. Peptides 1, 2 and 4 correspond to homo-dimeric interfaces, with $K_{\mathrm{d}}$ in the $\mu \mathrm{M}$ range for both the peroxiredoxin ${ }^{18}$ and $\beta$-lactoglobulin homodimers, ${ }^{19}$ but in the pm range for the umud' homodimer. ${ }^{20}$ However, peptide 3 was designed from a tetrameric interface, with a $K_{\mathrm{d}}$ dimer-tetramer still under debate, although suggested in the $\mu \mathrm{M}$ range. ${ }^{16}$

The correlation between the peptide relative behaviour in solution and the type of oligomeric interface supports that these sequences are tectons with native intrinsic assembly properties derived from the parent interfaces. The results presented herein augur well for other peptide sequences derived from protein interfaces providing a rich source of useful self-assembling tectons.

\section{Notes and references}

1 I. M. A. Nooren and J. M. Thornton, J. Mol. Biol., 2003, 325, 991-1018.

2 C. Chothia and J. Janin, Nature, 1975, 256, 705-708.

3 S. Dey, A. Pal, P. Chakrabarti and J. Janin, J. Mol. Biol., 2010, 398, 146-160.

4 E. H. C. Bromley, K. Channon, E. Moutevelis and D. N. Woolfson, ACS Chem. Biol., 2008, 3, 38-50.

5 C. Valery, F. Artzner and M. Paternostre, Soft Matter, 2011, 7, 9583-9594.

6 M. R. Ghadiri, J. R. Granja, R. A. Milligan, D. E. McRee and N. Khazanovich, Nature, 1993, 366, 324-327.

7 M. Reches and E. Gazit, Science, 2003, 300, 625-627.

8 K. Lu, J. Jacob, P. Thiyagarajan, V. P. Conticello and D. G. Lynn, J. Am. Chem. Soc., 2003, 125, 6391-6393.

9 I. W. Hamley, G. Cheng, V. Castelletto, S. Handschin and R. Mezzenga, Chem. Commun., 2012, 48, 3757-3759.

10 C. Valery, M. Paternostre, B. Robert, T. Gulik-Krzywicki, T. Narayanan, J. C. Dedieu, G. Keller, M. L. Torres, R. Cherif-Cheikh, P. Calvo and F. Artzner, Proc. Natl. Acad. Sci. U. S. A., 2003, 100, 10258-10262.

11 W. Van Grondelle, C. L. Iglesias, E. Coll, F. Artzner, M. Paternostre, F. Lacombe, M. Cardus, G. Martinez, M. Montes, R. Cherif-Cheikh and C. Valery, J. Struct. Biol., 2007, 160, 211-223.

12 S. Vauthey, S. Santoso, H. Y. Gong, N. Watson and S. G. Zhang, Proc. Natl. Acad. Sci. U. S. A., 2002, 99, 5355-5360.

13 Z. B. Cao, A. W. Roszak, L. J. Gourlay, J. G. Lindsay and N. W. Isaacs, Structure, 2005, 13, 1661-1664.

14 J. J. Adams, B. F. Anderson, G. E. Norris, L. K. Creamer and G. B. Jameson, J. Struct. Biol., 2006, 154, 246-254.

15 L. Vijayalakshmi, R. Krishna, R. Sankaranarayanan and M. Vijayan, Proteins: Struct., Funct., Bioinf., 2008, 71, 241-249.

16 S. Weyand, G. Kefala, D. Svergun and M. Weiss, J. Struct. Funct. Genomics, 2009, 10, 209-217.

17 A. E. Ferentz, G. C. Walker and G. Wagner, EMBO J., 2001, 20, 4287-4298.

18 S. Barranco-Medina, J. J. Lazaro and K. J. Dietz, FEBS Lett., 2009, 583, 1809-1816.

19 R. K. O. Apenten and D. Galani, Thermochim. Acta, 2000, 359, 181-188.

20 S. M. Simon, F. J. R. Sousa, R. Mohana-Borges and G. C. Walkers, Proc. Natl. Acad. Sci. U. S. A., 2008, 105, 1152-1157.

21 D. Hamada, T. Tanaka, G. G. Tartaglia, A. Pawar, M. Vendruscolo, M. Kawamura, A. Tamura, N. Tanaka and C. M. Dobson, J. Mol. Biol., 2009, 386, 878-890.

22 A. Mitraki and E. Kasotakis, in Self-Assembled Peptide Nanostructures, ed. J. Castillo, L. Sasso and W. E. Svendsen, Pan Stanford Publishing, 2013.

23 S. Krimm and J. Bandekar, Adv. Protein. Chem., 1986, 38, 181-364.

24 K. B. Andersen, J. Castillo-Leon, M. Hedstrom and W. E. Svendsen, Nanoscale, 2011, 3, 994-998. 